\title{
PEMANFAATAN ROTAN DAN BAMBU OLEH MASYARAKAT DESA PARIT RAJA KECAMATAN SEJANGKUNG KABUPATEN SAMBAS
}

\author{
(Utilization Of Rattan And Bamboo By The Community Of Parit Raja Village Of Sejangkung \\ Sub-District Sambas Regency)
}

\author{
Cici Suryani, Sofyan Zainal, Nurhaida \\ Fakultas Kehutanan Universitas Tanjungpura Jalan Imam Bonjol Pontianak. 78124 \\ Email: cicisuryani10081997@gmail.com
}

\begin{abstract}
Forests have the potential to meet a variety of human needs such as food, medicine, timber, and handicraft. Non-timber forest product used by the community of Parit Raja Village are rattan and bamboo. This research aim to inventory of the types of rattan and bamboo and to inventory the forms of utilization of rattan and bamboo processing in Parit Raja Village of Sejangkung Sub-District of Sambas Regency. This study used a survey method with in-depth interviews with the community in Parit Raja Village. The results showed that there were 5 types of rattan and 3 types of bamboo that were utilized by people of Parit Raja Village, namely Seuti Rattan (Calamus ornatus), Marau Rattan (Korthalsia rigida), Sega Rattan (Calamus caesius), Babuai Rattan (Plectocomia elongate), Nanga Rattan (Korthalsia Junghuhnii) and Bambo, namely Abe Bamboo (Gigantochloa Balui), Kuayan Bamboo, Ater Bamboo (Gigantochloa atter). The forms of utilization of rattan by Parit Raja Village community are the furniture, living room decoration and wicker found in the Sejangkung Hamlet. The most common type of rattan used were Seuti (99.9\%), while bamboo utilization ranged from furniture, wicker and cooking as found in Gambir Hamlet, Kawakan Hamlet, Sembuai Hamlet, and Rambayan Hamlet. The most commonly used bamboo species is Abe bamboo (93,3\%). There are 22 handicraft product produced by the people of Parit Raja Village including sofa sets, baby swing baskets, room dividers, corner shelves, flower vases (cage model), and parcels. The forms of utilization of bamboo by the community of Parit Raja Village: there are 14 handicraft products including nyiru, capil/tanggoi, rice dishes, small rice basket, bakak ( large rice basket), and fruit basket.
\end{abstract}

Keywords: Rattan, Bamboo, Parit Raja Village, Handicrafts.

\section{PENDAHULUAN}

Hutan memiliki potensi untuk memenuhi berbagai kebutuhan manusia seperti makanan, obat-obatan, papan, serta kerajinan tangan. Hutan tidak hanya ditumbuhi tumbuhan yang berkayu, hutan Indonesia mempunyai hasil hutan bukan kayu yang cukup berlimpah sedangkan pemanfaatannya belum optimal karena yang cenderung dimanfaatkan hanyalah pada hasil hutan kayu. Pemanfaatan hasil hutan non- kayu di Indonesia sudah sejak lama dilakukan oleh penduduk sekitar hutan untuk memenuhi kebutuhan hidup sehari-hari. Salah satu hasil hutan nonkayu yang dikenal oleh masyarakat sekitar hutan yaitu rotan dan bambu.

Rotan merupakan salah satu tumbuhan hutan bernilai komersil cukup tinggi, yang umumnya tumbuh secara alami di daerah dataran rendah maupun daerah pegunungan, memiliki banyak manfaat bagi masyarakat. 
Hampir seluruh bagian rotan dapat digunakan baik sebagai konstruksi kursi dan pengikat (Kusnaedi \& Pramudita, 2013). Jumiati et al. (2012) salah satu sumber hasil hutan non-kayu yang dimanfaatkan oleh masyarakat adalah spesies-spesies rotan yang banyak digunakan baik sebagai bahan anyaman, keperluan tali temali maupun untuk dijadikan bahan sayuran.

Rotan sangat potensial untuk dikembangkan sebagai bahan perdagangan, baik untuk kebutuhan dalam negeri maupun untuk ekspor (Januminro, 2009). Pemanfaatan sumberdaya alam oleh masyarakat lokal khususnya dalam pemanfaatan hasil hutan bukan kayu seperti tanaman rotan dan bambu belum banyak dikaji dan didokumentasikan di Indonesia. Data survey inventarisasi rotan sejak tahun 1990 sampai 2010 menunjukkan bahwa sebaran rotan di Kalimantan Barat pada umumnya berada di hutan rawa dan sebagian di hutan lahan kering (Sardana, dkk, 2011).

Bambu merupakan produk hasil hutan non kayu yang memiliki sifatsifat yang baik untuk dimanfaatkan, karena memiliki batang yang kuat. Rotan dan bambu merupakan bahan lokal yang memegang peranan sangat penting dalam kehidupan masyarakat, khususnya masyarakat Desa Parit Raja Kecamatan Sejangkung Kabupaten Sambas, ini dapat dilihat dari banyaknya penggunaan rotan dan bambu pada berbagai keperluan masyarakat, misalnya untuk memenuhi kebutuhan pangan, sandang, dan kerajinan tangan.

Rotan mempunyai manfaat yang beragam dalam kehidupan. Beberapa manfaat rotan adalah sebagai kerajinan tangan. Rotan ketika di ambil dari hutan alami atau budidaya perlu melewati proses pengolahan yang cukup panjang. Dimulai dari proses penggorengan kayu rotan, pengeringan, pelurusan kayu, pemutihan, hingga pengawetan kayu. Kesemuanya dilakukan agar rotan bisa di gunakan untuk bahan baku seperti kerajinan tangan yang membutuhkan bahan yang kuat dan elastis.

Secara tidak langsung, rotan berkontribusi dalam meningkatkan penghasilan masyarakat diwilayah sekitar hutan, juga berperan dalam membentuk budaya masyarakat, social, dan ekonomi sehingga rotan juga memiliki kelebihan yang mudah dibentuk karena sifatnya liat/kuat (Januminro 2000).

Dalam kehidupan masyarakat pedesaan di Indonesia bambu memegang peranan yang sangat penting. Bahan bambu dikenal oleh masyarakat memiliki sifat-sifat yang baik untuk dimanfaatkan antara lain : batangnya kuat, lurus, rata, keras, mudah dibelah, mudah dibentuk, dan mudah dikerjakan serta mudah diangkut. Selain itu bambu juga relative murah dibanding bahan bangunan lain karena banyak ditemukan disekitar pemukiman pedesaan. Bambu menjadi tanaman serbaguna bagi masyarakat pedesaan. Berbagai macam kegunaan bambu masih dapat dilihat pada daerah 
pedesaan diseluruh Indonesia, alat-alat dapur yang terbuat dari bambu seperti ayakan, bakul, nyiru, kukusan, tudung saji, dinding rumah, tiang, lantai, dan lain-lain.

Kontribusi tanaman rotan dan rotan di Kecamatan Sejangkung sangat berpengaruh dalam meningkatkan pendapatan masyarakat, khususnya masyarakat Desa Parit Raja. Selain sebagai petani, mereka memiliki pekerjaan sampingan, yaitu menjadi pengrajin rotan dan bambu. Tujuan dari penelitian yaitu inventarisasi jenis rotan dan bambu serta inventarisasi bentuk pemanfaatan dari pengolahan rotan dan bambu di Desa Parit Raja Kecamatan Sejangkung Kabupaten Sambas. Manfaat dari penelitian ini adalah memberikan informasi tentang inventarisasi jenis rotan dan bambu yang dimanfaatkan masyarakat Desa Parit Raja kepada masyarakat luas, memberikan informasi tentang bentuk- bentuk pemanfaatan dari pengolahan kerajinan rotan dan bambu yang dibuat oleh masyarakat Desa Parit Raja, dan Bagi pihak terkait, hasil penelitian ini bisa dijadikan masukan dalam mengoptimalkan hasil rotan dan bambu untuk masyarakat Desa Parit Raja.

\section{METODE PENELITIAN}

Desa Parit Raja merupakan salah satu Desa yang terletak di Kecamatan Sejangkung Kabupaten Sambas Provinsi Kalimantan Barat. Desa Parit Raja memiliki 5 Dusun yaitu : Dusun Sejangkung, Dusun Gambir, Dusun Kawakan, Dusun Sembuai, dan Dusun Rambayan. Desa ini terletak pada posisi $1^{\circ} 27^{\prime} 7,08^{\prime \prime}$ Lintang Utara serta $1^{\circ} 24^{\prime} 18,81^{\prime} \quad$ Lintang Utara dan $109^{\circ} 18^{\prime} 45,47^{\prime}$ ' Bujur Timur serta $109^{\circ} 22^{\prime} 57,37^{\prime \prime}$ Bujur Timur dengan luas wilayah $33,50 \mathrm{~km}^{2}(3.350 \mathrm{Ha})$ berdasarkan data Monografi Desa Parit Raja Kecamatan Sejangkung pada tahun 2019.

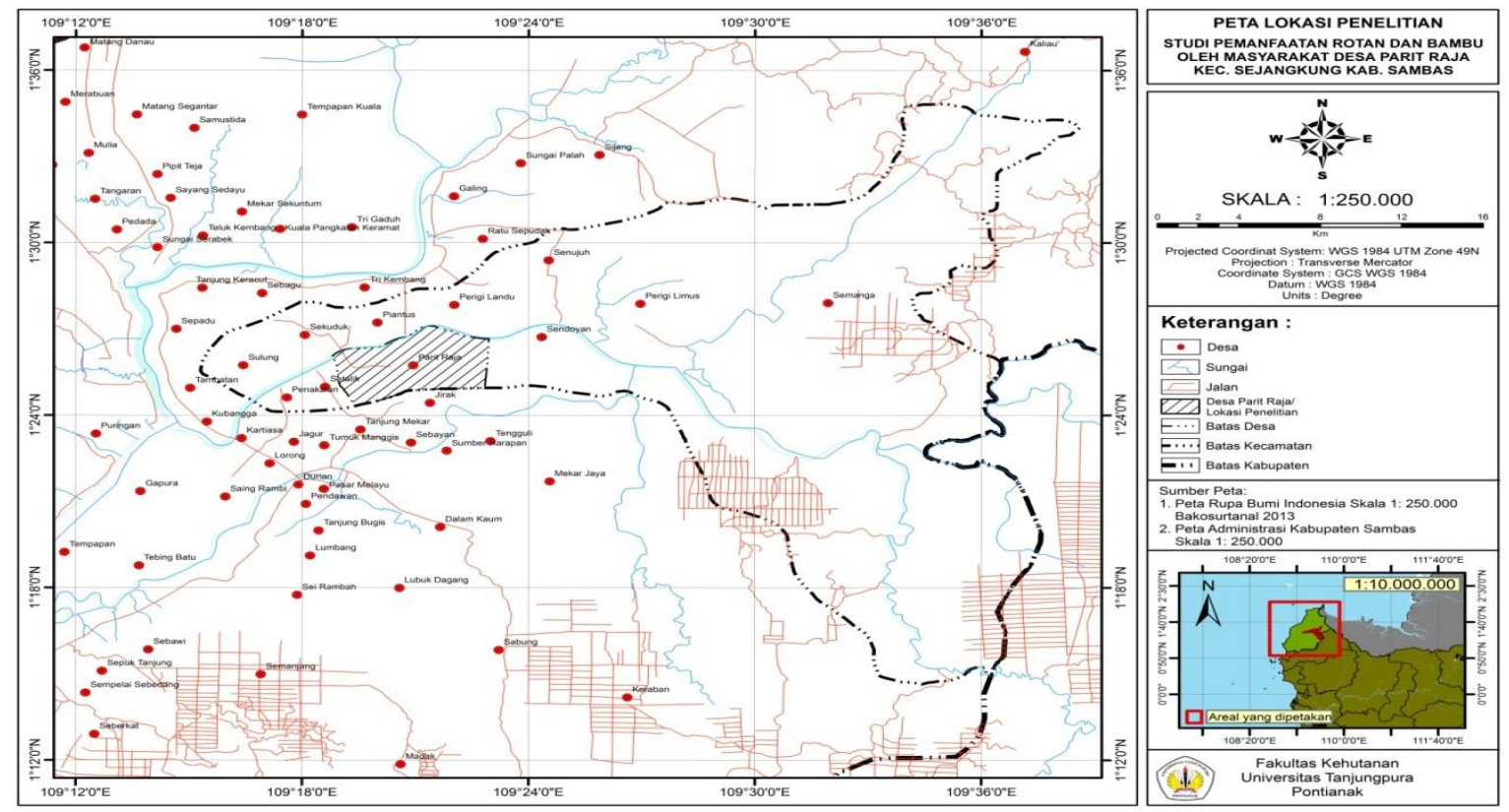

Gambar 1. Peta Lokasi Desa Parit Raja (Location Map of the Parit Raja Village) 
Penelitian dilaksanakan di Desa Parit Raja dengan waktu penelitian 1 bulan efektif dilapangan. Subjek penelitian adalah masyarakat yang berdomisili di Desa Parit Raja yang memanfaatkan rotan dan bambu, objek penelitian adalah rotan serta bambu yang tumbuh diwilayah Desa Parit Raja Kecamatan Sejangkung. Alat yang digunakan pada saat penelitian adalah kuisioner, atk, kamera digital, buku kunci identifikasi, parang, sepatu bot, dan peta lokasi.

Metode yang digunakan dalam penelitian ini adalah metode survei. Metode survei merupakan pengumpulan data primer berdasarkan komunikasi antara peneliti dengan responden (subjek). Teknik pengumpulan data yang digunakan pada penelitian adalah teknik wawancara dan teknik kuisioner. Penentuan jumlah responden dilakukan dengan Rumus Slovin dan pemilihan sampel responden yang dilakukan secara Purposive Sampling dengan tingkat kepercayaan $90 \%$ berdasarkan jumlah KK per dusun di Desa Parit Raja. Perhitungan dilakukan dengan menggunakan Rumus Slovin sebagai berikut:

Rumus Slovin:

$$
\mathrm{n}=\frac{\mathrm{N}}{1+N e^{2}}
$$

$\mathrm{n}=$ Ukuran sampel / jumlah responden

$\mathrm{N}=$ Ukuran populasi

$\mathrm{E}=$ Error (persen kelonggaran)
Berdasarkan perhitungan dengan menggunakan rumus slovin maka diperoleh jumlah responden sebanyak 90 KK dari 948 KK yang ada. Kriteria responden meliputi: kepala keluarga dan Ibu rumah tangga atau masyarakat yang sudah berkeluarga, sehat jasmani dan rohani, berdomisili minimal 5 tahun di Desa Parit Raja Kecamatan Sejangkung Kabupaten Sambas dan memanfaatkan rotan dan bambu setiap hari.

Analisis dilakukan secara deskriptif pada manfaat rotan dan bambu, bentuk bentuk kerajinan yang dihasilkan, bagian apa saja yang dimanfaatkan, dan rekapitulasi jenis-jenis tanaman rotan dan bambu yang terdapat di Desa Parit Raja Kecamatan Sejangkung Kabupaten Sambas. Didasarkan pada hasil informasi dilapangan yang dilakukan dengan wawancara secara langsung kepada masyarakat dan dengan cara pengumpulan data responden kuisioner.

\section{HASIL DAN PEMBAHASAN}

Jenis Rotan dan Bambu yang di Manfaatkan oleh Masyarakat Desa Parit Raja

Hasil penelitian terdapat 5 Jenis rotan yaitu 2 jenis berasal dari genus Calamus, 2 jenis dari genus Korthalsia, dan 1 jenis dari genus Plectocomia dan 3 jenis bambu yaitu 2 jenis genus Gigantochloa, 1 jenis genus Dendrocalamus. Rotan dan bambu yang di manfaatkan masyarakat di sajikan pada Tabel 1 . 
Tabel 1. Jenis Rotan dan Bambu yang Dimanfatkan Masyarakat (Types of Rattan and Bamboo Utilized by the Community)

\begin{tabular}{ccccc}
\hline No & Jenis & Nama Lokal & Nama Umum & Nama Ilmiah Rotan \\
\hline 1. & Rotan & Seuti & Seuti & Calamus ornatus \\
& & Marau & Marau & Korthalsia rigida \\
& Sega & Sega & Calamus caesius \\
& & Semuai & Babuai & Plectocomia elongate \\
& & Nanga & Nanga & Korthalsia junghuhnii \\
\hline 2. & Bambu & Abek & Abe & Gigantochloa balui \\
& Kuayan & Kuayan & \\
& Parring & Ater & Gigantochloa atter \\
\hline
\end{tabular}

bahwa di Desa Parit Raja ada 5 jenis rotan yang dimanfaatkan yaitu Rotan Seuti, Rotan Marau, Rotan Sega, Rotan Babuai, dan Rotan Nanga, Hasil penelitian juga menunjukkan bahwa di Desa Parit Raja ada 3 jenis bambu yang dimanfaatkan yaitu Bambu Abe, Bambu Kuayan, dan Bambu Ater. Keberadaan rotan dan bambu tersebut tampak membawa arti cukup penting bagi masyarakat Desa Parit Raja. Pemanfaatan rotan yang dilakukan oleh masyarakat Desa Parit Raja mulai dari perabotan, hiasan ruang tamu dan anyaman, untuk jenis rotan yang paling banyak digunakan adalah rotan jenis Seuti (90,9\%). Untuk pemanfaatan bambu mulai dari perabotan, anyaman dan masakan. Paling banyak digunakan adalah bambu jenis Abe (93,3\%). Bambu jenis Ater hanya dimanfaatkan rebung nya untuk masakan.

Berdasarkan hasil wawancara dengan masyarakat bahwa bagian yang digunakan dari rotan adalah batangnya karena pada bagian batang adalah bahan baku utama dalam pembuatan kerajinan berbagai bentuk dari olahan rotan dan bambu. Bagian bambu yang digunakan adalah batang dan rebungnya, hal ini sejalan dengan penelitian Linda (2017) rebung merupakan tunas bambu muda yang enak dimakan, biasanya dimanfaatkan sebagai bahan masakan, terutama untuk dibuat sayur. Batang rotan dan bambu dimanfaatkan secara komersial untuk anyaman kerajinan tangan karena kekuatan, kelenturan dan keseragamannya sehingga rotan dan bambu baik digunakan dalam keadaan utuh maupun dalam belahan. Hal ini sejalan dengan penelitian Gusniati (2017) di Desa Kasromego yaitu bagian-bagian rotan yang biasa digunakan sebagian besar adalah pada bagian batangnya.

\section{Proses Pengolahan Rotan dan Bambu oleh Masyarakat}

Proses pengolahan rotan dan bambu yang ada di Desa Parit Raja termasuk pengolahan rotan habis panen dihutan atau proses pengolahan rotan rumahan secara tradisional harus melewati proses-proses seperti : proses pemanenan, proses pembersihan, proses pengeringan dan proses penganyaman.

- Rotan

Rotan yang siap dipanen merupakan rotan yang sudah masak tebang baik yang berada dihutan maupun dikebun masyarakat. Cara 
membedakan rotan yang siap dipanen dengan rota yang masih muda biasanya masyarakat setempat melihat langsung dari warna daun. Warna daun rotan yang sudah masak tebang biasanya mulai mengering dengan berwarna keabu-abuan, kekuning-kuningan dan sudah banyak daun dan duri yang gugur. Teknik pengambilan rotan dengan memotong bagian pangkal pohon rotan, ditarik sampai seluruh bagian rotan rotan terlihat, kemudian rotan digosok-gosokan pada batang atau kayu terus kemudian memotong bagian ujung rotan, rotan tersebut digulung dan siap digunakan.

- Bambu

Proses penebangan yang dilakukan oleh masyarakat setempat dilakukan secara sederhana dan hanya dilengkapi peralatan parang, pisau, sarung tangan dan alas kaki. Bambu ditebang pangkalnya dipilih kemudian batang ditarik kebawah agar terlepas dari penyanggah. Menurut Kanisius (2005), proses penebangan bambu harus dimulai pada rumpun pinggir (tepi) dan tanaman bambu yang tumbuh tidak menjulang atau menindih tanaman bambu lain. Penebangan bambu dilakukan dengan cara menebas dengan parang pada sisi bawah lengkungan batang bambu membentuk luka segitiga siku-siku sampai poros bambu nyaris putus pada jarak satu ruas diatas pangkal batang, kemudian tebaskan parang pada sisi atas (lengkungan) batang sampai poros bambu putus dari pangkal batang.

Pemanfaatan Rotan dan Bambu oleh Masyarakat

Berdasarkan hasil penelitian, bentuk pemanfaatan rotan dan bambu yang dihasilkan oleh masyarakat Desa Parit Raja ada 22 produk dan pemanfaatan bambu sebanyak 15 produk (Gambar 2) dan (Gambar 3). Untuk lebih jelasnya dapat dilihat pada Tabel 2 dan Tabel 3. 
Tabel 2. Bentuk-Bentuk Kerajinan Rotan di Desa Parit Raja (Froms of Rattan Handicrafts in Parit Raja Village)

\begin{tabular}{|c|c|c|c|c|c|c|}
\hline \multirow{2}{*}{ No } & \multirow{2}{*}{ Kerajinan Rotan } & \multicolumn{5}{|c|}{ Jenis Tanaman Rotan } \\
\hline & & Seuti & Marau & Sega & Babuai & Nanga' \\
\hline 1. & Kursi sofa / set & $\sqrt{ }$ & $\sqrt{ }$ & - & - & - \\
\hline 2. & Kursi sudut / set & $\sqrt{ }$ & $\sqrt{ }$ & - & - & - \\
\hline 3. & Kursi bakul / set & $\sqrt{ }$ & - & - & - & - \\
\hline 4. & Kursi skeram / set & $\sqrt{ }$ & - & - & - & - \\
\hline 5. & Kursi parabola / set & $\sqrt{ }$ & - & - & - & - \\
\hline 6. & Keranjang ayunan bayi & $\sqrt{ }$ & - & $\sqrt{ }$ & - & - \\
\hline 7. & Kursi bar / café & $\sqrt{ }$ & - & - & - & - \\
\hline 8. & Sekat ruangan & $\sqrt{ }$ & - & $\sqrt{ }$ & - & - \\
\hline 9. & Miniature sepeda hias & $\sqrt{ }$ & - & - & - & - \\
\hline 10. & Tempat gelas aqua & $\sqrt{ }$ & - & - & - & - \\
\hline 11. & Vas bunga & $\sqrt{ }$ & - & - & - & - \\
\hline 12. & Rak sudut & $\sqrt{ }$ & - & $\sqrt{ }$ & - & - \\
\hline 13. & Kuda lumping & $\sqrt{ }$ & - & - & - & - \\
\hline 14. & Ayunan dewasa & $\sqrt{ }$ & $\sqrt{ }$ & - & - & - \\
\hline 15. & Keranjang buah & $\sqrt{ }$ & - & $\sqrt{ }$ & - & - \\
\hline 16. & Vas bunga(model sangkar) & $\sqrt{ }$ & - & $\sqrt{ }$ & - & - \\
\hline 17. & Kursi goyang & $\sqrt{ }$ & - & - & - & - \\
\hline 18. & Box bayi & $\sqrt{ }$ & - & - & - & - \\
\hline 19. & Parcel (hantaran) & $\sqrt{ }$ & - & $\sqrt{ }$ & - & - \\
\hline 20. & Sandal rotan & - & - & $\sqrt{ }$ & - & - \\
\hline 21. & Kap lampu & - & - & $\sqrt{ }$ & - & - \\
\hline 22. & Tudung saji & $\sqrt{ }$ & - & - & $\sqrt{ }$ & $\sqrt{ }$ \\
\hline & Jumlah & 20 & 3 & 8 & 1 & 1 \\
\hline & Persentase (\%) & $90,9 \%$ & $13,6 \%$ & $36,3 \%$ & $4.54 \%$ & $4,54 \%$ \\
\hline
\end{tabular}

Berdasarkan penelitian dilapangan menunjukan bahwa sebagian besar yang digunakan adalah rotan jenis Seuti yaitu 90,9 \% dan yang sedikit digunakan adalah jenis rotan babuai dan nanga yaitu $4.54 \%$ dari total 22 produk kerajinan tangan yang dihasilkan. Rotan seuti banyak digunakan karena rotan ini mudah didapat, mudah dianyam, dan serbaguna (berkualitas) sehingga lebih sering dipergunakan masyarakat untuk menganyam dan sebagai bahan pengikat, selain itu juga bisa digunakan untuk membuat hampir semua jenis anyaman. Sedangkan untuk jenis rotan babuai dan nanga sedikit digunakan karena hanya digunakan untuk tali pengikat dan bingkai untuk pembuatan produk tudung saji saja dan lebih banyak dipergunakan pada produk kerajinan bambu. 


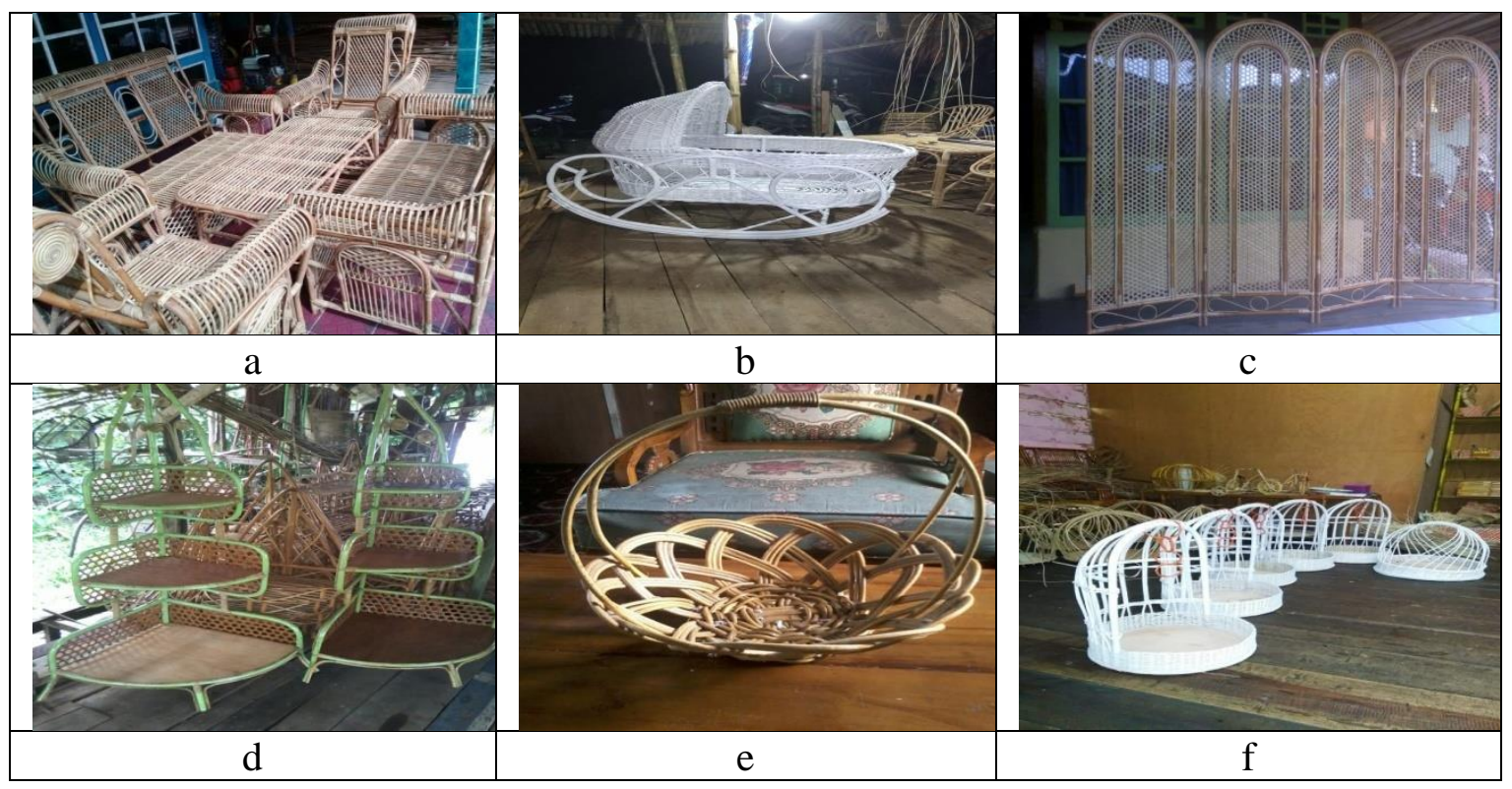

Gambar 2 : (a). kursi sofa/set (b). keranjang ayunan bayi (c). sekat ruangan (d). rak sudut (e).keranjang buah (f). parcel (hantaran)

Tabel 3. Bentuk-Bentuk Kerajinan Bambu di Desa Parit Raja (Froms of Bamboo Handicrafts in Parit Raja Village)

\begin{tabular}{|c|c|c|c|c|}
\hline \multirow{2}{*}{ No } & \multirow{2}{*}{ Kerajinan Bambu } & \multicolumn{3}{|c|}{ Jenis Tanaman Bambu } \\
\hline & & Abe & Kuayan & Ater \\
\hline 1. & Nyiru’ & $\sqrt{ }$ & $\sqrt{ }$ & - \\
\hline 2. & Capil / tanggoi & $\sqrt{ }$ & $\sqrt{ }$ & - \\
\hline 3. & Ayakan & $\sqrt{ }$ & - & - \\
\hline 4. & Bakul kecil bertutup & $\sqrt{ }$ & - & - \\
\hline 5. & Piring nasi presmanan & $\sqrt{ }$ & - & - \\
\hline 6. & Ragak sedang bertutup & $\sqrt{ }$ & - & - \\
\hline 7. & Bakul kecil & $\sqrt{ }$ & - & - \\
\hline 8. & Ragak selengka & $\sqrt{ }$ & - & - \\
\hline 9. & Bakak (bakul besar) & $\sqrt{ }$ & - & - \\
\hline 10. & Lembaran kain (kopiah, dompet, tas) & $\sqrt{ }$ & $\sqrt{ }$ & - \\
\hline 11. & Keranjang buah (oval, bulat, segi) & $\sqrt{ }$ & $\sqrt{ }$ & - \\
\hline 12. & Candi (vas bunga) besar & $\sqrt{ }$ & $\sqrt{ }$ & - \\
\hline 13. & Candi (vas bunga) kecil & $\sqrt{ }$ & $\sqrt{ }$ & - \\
\hline 14. & Masakan / Acar & - & - & $\sqrt{ }$ \\
\hline 15. & Tudung saji & $\sqrt{ }$ & - & - \\
\hline & Jumlah & 14 & 6 & 1 \\
\hline & Persentase (\%) & $93,3 \%$ & $40 \%$ & $6,66 \%$ \\
\hline
\end{tabular}

Berdasarkan penelitian dilapangan menunjukan bahwa sebagian besar yang digunakan adalah bambu jenis Abe yaitu 93,3 \% dan yang sedikit digunakan adalah jenis bambu ater yaitu hanya $6,66 \%$ dari total 15 produk yang 
dihasilkan. Bambu abe ini mudah didapat, mudah dibentuk, dan mudah dianyam. Bambu abe banyak digunakan karena bambu ini hampir di setiap kebun masyarakat menanam bambu abe, juga bisa digunakan hampir smua jenis anyaman yang dihasilkan

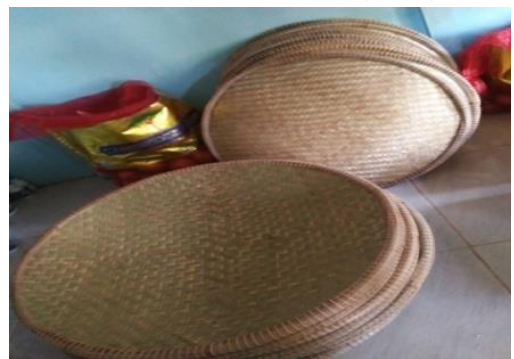

a

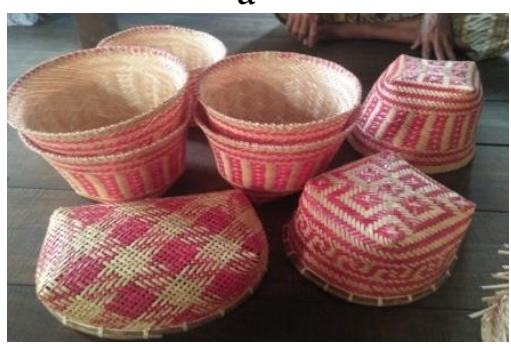

d

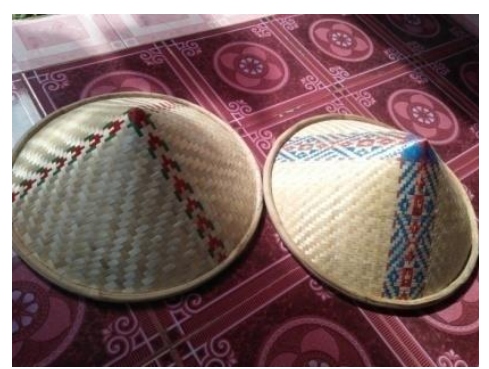

b

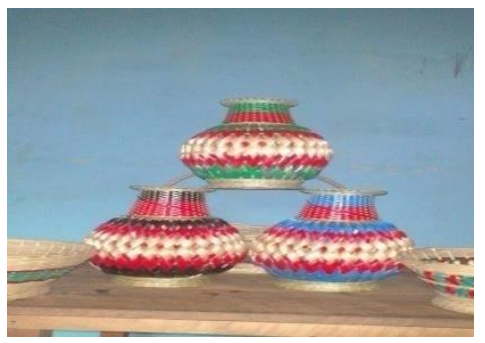

e menggunakan bambu abe ini. Sedangkan untuk bambu jenis ater ini sedikit digunakan dan hanya dimanfaatkan untuk masakan saja itupun hanya beberapa orang saja yang memanfaatkan nya.

Gambar 3 : (a). nyiru (b). capil/tanggoi (c). piring nasi presmanan (d). bakul kecil (e).candi (vas bunga) (f). keranjang buah

Berdasarkan data pada Tabel 2, jenis rotan yang banyak dimanfaatkan adalah rotan jenis Seuti yang menghasilkan 20 produk kerajinan tangan dan yang paling sedikit yang dimanfaatkan masyarakat adalah rotan jenis Babuai. Rotan babuai hanya dimanfaatkan sebagai bahan tali pengikat untuk produk tudung saji. Hasil pemanfaatan rotan di Desa Parit Raja lebih banyak di bandingkan dengan pemanfaatan rotan oleh Masyarakat Suku Dayak Kanayatn yang memanfaatkan rotan jenis Seuti yang hanya menghasilkan 5 produk kerajinan tangan (Simanjuntak, 2016).

Berdasarkan data pada Tabel 3, jenis bambu yang banyak dimanfaatkan adalah bambu jenis Abe menghasilkan 14 produk kerajinan tangan dan yang paling sedikit dimanfaatkan adalah bambu jenis Ater hanya 1 produk yaitu sebagai bahan masakan. Hasil pemanfaatan bambu di Desa Parit Raja lebih banyak dibandingkan dengan pemanfaatan bambu di Desa Sedahan Jaya yang hanya memanfaatkan bambu untuk 10 produk kerajinan tangan (Linda, 2017).

Pemanfaatan rotan dan bambu yang dilakukan di Desa Parit Raja saat ini merupakan turun temurun dari nenek moyang mereka yang berasal dari hasil interaksi mereka dengan alam sekitarnya. Saat ini bentuk kearifan lokal yang masih ada di Desa Parit Raja khususnya pemanfaatan rotan dan bambu adalah kesadaran untuk menjaga kelestarian spesies tanaman rotan dan bambu yang digunakan. Umumnya pewarisan 
pengetahuan tradisional dilakukan secara lisan dari generasi ke generasi (Soekarman dan Riswan,1992).

Pemungutan hasil rotan dan bambu yang diperoleh dari hutan dan kebun masyarakat itu sendiri merupakan pekerjaan yang dilakukan masyarakat sekitar.dalam hal pemenuhan kebutuhan sehari-hari. Kebiasaan adat mereka mengambil rotan dan bambu secara terbatas sesuai dengan keperluan untuk membuat produk anyaman / kerajinan. Rotan dan bambu yang diambil hanya rotan dan bambu yang masak tebang saja, anakan rotan dan bambu tidak boleh diambil agar rotan dan bambu tetap terjaga kelestariannya, beda untu jenis bambu yang di ambil tunas(rebung)nya untuk dijadikan sayur. Pengolahan pertama rotan dan bambu yang dilakukan dihutan dan dikebun masyarakat itu sendiri merupakan langkah awal yang sangat penting dalam hal penentuan kualitas rotan dan bambu.

Bentuk produk yang dihasilkan dari kerajinan rotan dan bambu tersebut biasanya di pakai sendiri dan dijual, rotan dan bambu yang dijual tergantung pemesanan, ada yang murah dan ada juga yang mahal. Kebanyakan masyarakat menjual hasil kerajinan rotan dan bambu tersebut untuk menambah perekonomian mereka . Hasil pendapatan masyarakat di Desa Parit Raja dapat dilihat pada Tabel 4,5 dan 6 berikut ini.

Tabel 4. Rekapitulasi Hasil Pendapatan Masyarakat (Recapitulation of Community Income)

1. Produk Rotan

\begin{tabular}{lllll}
\hline No & Bentuk Pemanfaatan & $\begin{array}{c}\text { Total } \\
\text { Penerimaan } \\
\text { ( TR) }\end{array}$ & $\begin{array}{c}\text { Total biaya } \\
\text { (TC) }\end{array}$ & $\begin{array}{c}\text { Pendapatan } \\
\text { (I) }\end{array}$ \\
\hline 1. & Kursi Sofa / Set & Rp. 2.200 .000 & Rp. 1.100 .000 & Rp. 1.100 .000 \\
2. & Kursi Sudut / Set & Rp. 2.200 .000 & Rp. 1.100 .000 & Rp. 1.100 .000 \\
3. & Kursi Bakul / Set & Rp. 1.800 .000 & Rp. 900.000 & Rp. 900.000 \\
4. & Kursi Skeram / Set & Rp. 1.800 .000 & Rp. 900.000 & Rp. 900.000 \\
5. & Kursi Parabola / Set & Rp. 1.200 .000 & Rp. 600.000 & Rp. 600.000 \\
6. & Keranjang Ayunan Bayi & Rp. 400.000 & Rp. 190.000 & Rp. 210.000 \\
7. & Kursi Bar / Café & Rp. 150.000 & Rp. 60.000 & Rp. 90.000 \\
8. & Sekat Ruangan & Rp. 250.000 & Rp. 100.000 & Rp. 150.000 \\
9. & Miniature Sepeda Hias & Rp. 80.000 & Rp. 30.000 & Rp. 50.000 \\
10. & Tempat Aqua & Rp. 80.000 & Rp. 35.000 & Rp. 45.000 \\
11. & Vas Bunga & Rp. 170.000 & Rp. 75.000 & Rp. 95.000 \\
12. & Rak Sudut & Rp. 150.000 & Rp. 75.000 & Rp. 75.000 \\
13. & Kuda Lumping & Rp. 80.000 & Rp. 40.000 & Rp. 40.000 \\
14. & Ayunan Dewasa & Rp. 350.000 & Rp. 150.000 & Rp. 200.000 \\
15. & Keranjang Buah & Rp. 45.000 & Rp. 22.000 & Rp. 23.000 \\
16. & Vas bunga (model & Rp. 120.000 & Rp. 50.000 & Rp. 70.000 \\
& Sangkar) & Rp. 400.000 & Rp. 170.000 & Rp. 230.000 \\
17. & Kursi Goyang & Rp. 250.000 & Rp. 100.000 & Rp. 150.000 \\
18. & Box Bayi & Rp. 75.000 & Rp. 35.000 & Rp. 40.000 \\
19. & Parcel (hantaran) & Rp. 95.000 & Rp. 20.000 & Rp. 75.000 \\
20. & Sandal Rotan & Rp. 90.000 & Rp. 30.000 & Rp. 60.000 \\
21. & Kap Lampu & Tam &
\end{tabular}

Ket $:$ I $=$ TR - TC I $=$ Pendapatan; TR $=$ Total Penerimaan; TC $=$ Total Biaya

Berdasarkan penelitian dilapangan harga jual yang termahal pada produk rotan yaitu kursi sofa / set dengan harga Rp 2.200.000 dan harga jual produk 
yang termurah yaitu keranjang buah dengan harga Rp 45.000. Kursi sofa/set dikatakan produk yang mahal dibanding produk lainnya karena proses pembuatannya memerlukan waktu yang lama dan termasuk pengolahan yang cukup sulit juga dibandingkan dengan produk lainnya, keranjang buah dikatakan produk yang termurah karena proses pembuatannya cepat dan tidak memakan waktu yang lama dalam proses pembuatannya.

Tabel 5. Rekapitulasi Hasil Pendapatan Masyarakat (Recapitulation of Community Income)

2. Produk Bambu

\begin{tabular}{lllll}
\hline No & Bentuk Pemanfaatan & $\begin{array}{c}\text { Total } \\
\text { Penerimaan } \\
\text { TR) }\end{array}$ & $\begin{array}{c}\text { Total biaya } \\
\text { (TC) }\end{array}$ & $\begin{array}{c}\text { Pendapatan } \\
\text { (I) }\end{array}$ \\
\hline 1. & Nyiru' & Rp. 20.000 & Rp. 8.000 & Rp. 12.000 \\
2. & Capil / Tanggoi & Rp. 15.000 & Rp. 8.000 & Rp. 7.000 \\
3. & Ayakan & Rp. 25.000 & Rp. 8.000 & Rp. 17.000 \\
4. & Bakul Kecil Bertutup & Rp. 10.000 & Rp. 3.000 & Rp. 7.000 \\
5. & Piring Nasi Presmanan & Rp. 15.000 & Rp. 5.000 & Rp. 10.000 \\
6. & Ragak Sedang Bertutup & Rp. 15.000 & Rp. 5.000 & Rp. 10.000 \\
7. & Bakul Kecil & Rp. 6.000 & Rp. 3.000 & Rp. 3.000 \\
8. & Ragak & Rp. 7.000 & Rp. 3.000 & Rp. 4.000 \\
9. & Bakak (bakul besar) & Rp. 40.000 & Rp 13.000 & Rp. 27.000 \\
10. Lembaran Kain (kopiah, & Rp. 20.000 & Rp. 8.000 & Rp. 12.000 \\
11. & Kempet, tas) & & & \\
& bulanj, segi) & Rp. 18.000 & Rp. 7.000 & Rp. 11.000 \\
12. Candi (vas bunga) besar & Rp. 60.000 & Rp. 15.000 & Rp. 45.000 \\
13. & Candi (vas bunga) kecil & Rp. 18.000 & Rp. 7.000 & Rp. 11.000 \\
\hline
\end{tabular}

Ket : I = TR - TC; I = Pendapatan; TR = Total Penerimaan; $\mathrm{TC}=$ Total Biaya

Berdasarkan penelitian dilapangan harga jual yang termahal pada produk bambu yaitu candi (vas bunga) besar dengan harga Rp 60.000 dan harga jual produk yang termurah yaitu bakul kecil dengan harga $\mathrm{Rp}$ 6.000. candi (vas bunga) besar dikatakan produk yang mahal dibanding produk lainnya karena proses pembuatannya memerlukan waktu yang lama dan dengan ukuran yang besar, bakul kecil dikatakan produk yang termurah karena proses pembuatannya cepat, ukurannya kecil dan tidak memakan waktu yang lama dalam proses pembuatannya. 
Tabel 6. Rekapitulasi Hasil Pendapatan Masyarakat (Recapitulation of Community Income)

3. Produk Kombinasi Rotan dan Bambu

\begin{tabular}{llccc}
\hline No & Bentuk Pemanfaatan & $\begin{array}{c}\text { Total } \\
\text { Penerimaan } \\
\text { ( TR) }\end{array}$ & $\begin{array}{c}\text { Total biaya } \\
\text { (TC) }\end{array}$ & $\begin{array}{c}\text { Pendapatan } \\
\text { (I) }\end{array}$ \\
\hline 1. & Tudung Saji & Rp. 150.000 & Rp. 75.000 & Rp. 75.000 \\
\hline
\end{tabular}

Ket : I = TR - TC; I = Pendapatan; TR = Total Penerimaan; TC = Total Biaya

Berdasarkan hasil penelitian dilapangan menyatakan bahwa harga jual produk kombinasi antara rotan dan bambu dengan memperoleh produk yaitu tudung saji dengan harga $\mathrm{Rp}$ 150.000, dari segi pengolahan juga tergolong cukup lama.

Produk rotan yang di hasilkan di Desa Parit Raja bervariasi tergantung dari bahan rotan itu sendiri tergantung dari banyak atau sedikitnya bahan baku yang dihasilkan dari hutan. Pasalnya naiknya harga bahan baku itu tidak diimbangi dengan naiknya harga jual produk kerajinan rotan. Penjualan produk tersebut juga tergantung pemesanan dari konsumen. Berbeda halnya dengan produk bambu yang di hasilkan masih sangat rendah dikarenakan bahan bambu di Desa Parit Raja tergolong berlimpah. Para pengrajin di Desa Parit Raja menjadikan pekerjaan menganyam ini sebagai salah satu sumber penghasilan mereka dan ada juga yang menjadikan pekerjaan ini sebagai sampingan untuk menambah perekonomian mereka.

\section{Kesimpulan}

Berdasarkan hasil Penelitian Pemanfaatan Rotan dan Bambu Oleh Masyarakat Desa Parit Raja Kecamatan
Sejangkung Kabupaten Sambas dapat disimpulkan sebagai berikut :

1. Berdasarkan data yang diperoleh dilokasi penelitian, tercatat ada 5 jenis rotan yang dimanfaatkan oleh masyarakat Desa Parit Raja, jenisjenis rotan tersebut adalah Rotan Seuti, Rotan Marau, Rotan Sega, Rotan Babuai, dan Rotan Nanga dan tercatat ada 3 jenis bambu yang dimanfaatkan oleh masyarakat Desa Parit Raja, jenis-jenis bambu tersebut adalah Bambu Abe, Bambu Kuayan, dan Bambu Ater.

2. Bentuk pemanfaatan rotan yang dihasilkan oleh masyarakat Desa Parit Raja ada 22 produk untuk saat ini khususnya di Dusun Sejangkung adalah kursi sofa, kursi sudut, kursi bakul, kursi skeram, kursi parabola, keranjang ayunan bayi, kursi bar/café, sekat ruangan, miniature sepeda hias, tempat aqua, vas bunga, rak sudut, kuda lumping, ayunan dewasa, keranjang buah, vas bunga(model sangkar), kursi goyang, box bayi, parcel (hantaran), tudung saji, sandal rotan, dan kap lampu dan untuk bambu yang dihasilkan oleh masyarakat Desa Parit Raja ada 14 produk untuk saat ini khususnya di Dusun Gambir, 
Dusun Kawakan, Dusun Sembuai dan Dusun Rambayan adalah nyiru', capil/tanggoi, ayakan, tudung saji, bakul kecil bertutup, piring nasi presmanan, ragak sedang bertutup, bakul kecil, ragak, bakak (bakul besar), lembaran kain(kopiah,dompet,tas), keranjang buah (oval,bulat,segi), candi (vas bunga) besar dan candi (vas bunga) kecil.

3. Pemanfaatan rotan yang dilakukan oleh masyarakat Desa Parit Raja mulai dari perabotan, hiasan ruang tamu dan anyaman, untuk jenis rotan yang paling banyak digunakan adalah rotan jenis Seuti (90,9\%). Untuk pemanfaatan bambu mulai dari perabotan, anyaman dan masakan. Paling banyak digunakan adalah bambu jenis Abe (93,3\%). Untuk bambu jenis Ater hanya dimanfaatkan untuk masakan saja itupun hanya beberapa responden saja yang memanfaatkan nya.

4. Rotan hanya dimanfaatkan oleh masyarakat di Dusun Sejangkung, sedangkan bambu dimanfaatkan oleh masyarakat Dusun Gambir, Dusun Kawakan, Dusun Sembuai dan Dusun Rambayan.

\section{Saran}

Berdasarkan hasil penelitian ini dikemukakan saran-saran sebagai berikut :

1. Pemanfaatan rotan dan bambu yang cukup banyak, maka diharapkan masyarakat Desa Parit Raja dapat melakukan pembudidayaan rotan dan bambu khususnya pada pada jenis jenis rotan dan bambu yang sering dimanfaatkan agar keberadaan rotan dan bambu tersebut tetap ada dan terus dimanfaatkan secara berkelanjutan.

2. Perlu pengkajian lebih dalam terhadap penetapan subjek terkait dengan pemanfaatan rotan dan bambu yang ada di Desa Parit raja.

3. Pemanfaatan rotan dan bambu yang memiliki nilai jual seperti halnya kerajinan tangan/anyaman, masyarakat dapat lebih mengenalkan produk-produk kerajinan tangan tersebut kepada masyarakat luar Desa Parit Raja. Agar masyarakat luar dapat lebih mengenal kerajinan-kerajinan tangan yang ada dan hal tersebut pastinya dapat membantu perekonomian masyarakat Desa Parit Raja dari hasil penjualan kerajinan tangan yang dilakukannya.

\section{DAFTAR PUSTAKA}

Gusniati, Zainal S, Fahrizal. 2017. Studi Pemanfaatan Rotan Oleh Masyarakat Setempat Pada Kawasan Hutan Desa Kasromego Kecamatan Beduai Kabupaten Sanggau. Jurnal Hutan Lestari 5(2):282-291.

Januminro. CFM. 2000. Rotan Indonesia Potensi Budidaya Pemungutan Pengolahan Standar Mutu dan Prospek Pengusahaan. Kanisius.Yogyakarta

Januminro. 2009. Keindahan Rotan Indonesia, Cara Mudah Membuat Anyaman dan Meubel Rotan. Kanisius. Yogjakarta. 
Jumiati, Hariyadi B, dan Murni P. 2012. Studi Etnobotani Rotan sebagai Bahan Kerajinan Anyaman pada Suku Anak Dalam (SAD) di Dusun III Senami, Desa Jebak, Kabupaten Batanghari, Jambi. Biospecies, vol. 5, no.1.

Kanisius. 2015. Aneka Anyaman Bambu. Yogyakarta : Teknologi Tepat Guna

Kusnaedi I dan Pramudita AS. 2013. Sistem Bending Pada Proses Pengolahan Kursi Rotan di Cirebon, Jurnal Rekajiva, vol. 1 no 2.

Linda F, Linda R, Rafdinal. 2017. Pemanfaatan Rotan dan Bambu yang Bernilai Ekonomis oleh Masyarakat Suku Dayak Kanayatn di Kecamatan Sengah Temila Kabupaten Landak. Jurnal Protobiont Vol 6 (3) : 233 - 239.

Sardana A, Dkk. 2011. Potret Hutan Propinsi Kalimantan Barat. Kementrian Kehutanan.

Simanjuntak N, Idham M, Ardian H. 2016 Pemanfaatan Rotan Sebagai Bahan Kerajinan Anyaman di Desa Sedahan Jaya Kecamatan Sukadana Kabupaten Kayong Utara. Jurnal Hutan Lestari Vol. 4 (3) : $344-351$.

Soekarman dan Riswan S. 1992. Status Pengetahuan Etnobotani di Indonesia. Di dalam: Seminar dan Lokakarya Nasional Etnobotani; Cisarua-Bogor, 19-20 Februari 1992. Bogor: Departemen Pendidikan dan Kebudayaan RI, Departemen Pertanian RI, LIPI, Perpustakaan Nasional RI.Hal: 17. 